\title{
DISCURSO POPULISTA EM CONSTRUÇÕES JORNALÍSTICAS ACERCA DO CACEROLAZO ARGENTINO E DO PANELAÇO BRASILEIRO
}

\author{
POPULIST DISCOURSE IN JOURNALISTIC \\ CONSTRUCTIONS ABOUT ARGENTINE \\ CACEROLAZO AND BRAZILIAN PANELAÇO
}

\author{
Antonio Andrade* \\ Priscila da Silva Marinho**
}

\section{RESUMO}

Este artigo debate a relação entre jornalismo, populismo e mídias digitais. Deste modo, observamos de que maneira os textos jornalísticos, ao produzirem narrativas acerca das manifestações sociopolíticas conhecidas como "cacerolazo", em 2012/2013 na Argentina, durante o governo de Cristina Kirchner, e "panelaço", em 2015 no Brasil, durante o governo de Dilma Rousseff, reforçam o processo de propagação de elementos discursivos que se imiscuem à lógica do populismo e se imbricam às dicções populistas do contemporâneo, que vêm sendo denominadas como populismo algorítmico e/ou populismo digital. Ao promoverem a circulação de certos dizeres (e não outros), partindo do efeito discursivo de evidência, como se fossem apenas "relatos de fatos", baseados na ilusão de neutralidade e imparcialidade, as construções jornalísticas produzem uma determinação dos sentidos, filiando-se a dadas práticas discursivas, sócio-historicamente marcadas. A atividade jornalística, ao se apropriar do discurso populista, contribui para a instalação no cenário político de polaridades e dicotomias que resultaram, no contexto argentino, na derrocada do kirchnerismo em 2015 e, no contexto brasileiro, no impeachment da presidenta Dilma Rousseff em 2016. A fim de ilustrarmos nossa discussão, analisaremos, a partir da perspectiva teórico-metodológica da Análise do Discurso, algumas manchetes, trechos de reportagens e fotografias, disponibilizados nos sites dos jornais argentinos Clarín e La Nación e nos jornais brasileiros Folha de S. Paulo e O Globo, na época dos eventos mencionados.

Palavras-chave: cacerolazo argentino e panelaço brasileiro; jornalismo; discurso populista.

\section{ABSTRACT}

This paper discusses the relationship among journalism, populism and digital media. Thus, we observe how the journalistic texts, when producing narratives about the socio-political manifestations known as "cacerolazo", in 2012/2013 in Argentina, during the government

\footnotetext{
* Universidade Federal do Rio de Janeiro, Rio de Janeiro, RJ, Brasil. antonioandrade.ufrj@gmail.com Bolsista de produtividade do $\mathrm{CNPq}$.

Orcid: https://orcid.org/0000-0003-1126-9630

** Universidade Federal do Rio de Janeiro, Rio de Janeiro, RJ, Brasil. priscilasilvamarinho@globomail.com Orcid: https://orcid.org/0000-0001-6079-6336
} 
of Cristina Kirchner, and "panelaço", in 2015 in Brazil, during the government of Dilma Rousseff, reinforce the process of propagation of discursive elements that meddle with the logic of populism and intertwine with the populist tendencies of the contemporary, which have been called algorithmic populism and/or digital populism. By promoting the circulation of certain speeches (and not others), under the discursive effect of evidence, as if they were only "facts reports", based on the illusion of neutrality and impartiality, the journalistic constructions produce a determination of meanings, that are affiliated with given discursive practices, marked in a socio-historical way. The journalistic activity when appropriating the populist discourse contributes to the installation of polarities and dichotomies in the political scenario that resulted, in the Argentine context, to the collapse of Kirchnerism in 2015, and in the Brazilian context, to the impeachment of President Dilma Rousseff in 2016. In order to illustrate our discussion, we will analyze, from the theoretical-methodological perspective of Discourse Analysis, some headlines, excerpts from reports and photographs, available on the websites of the Argentine newspapers Clarin and La Nación and the Brazilian newspapers Folba de S. Paulo and O Globo, at the time of the mentioned events.

Keywords: Argentine cacerolazo and Brazilian panelaço; jornalism; populist discourse.

\section{INTRODUÇÃO}

O objetivo deste artigo é refletir acerca da maneira como os textos jornalísticos, ao (re)criarem as manifestações sociopolíticas conhecidas como cacerolazo, em 2012/2013 na Argentina, durante o governo de Cristina Kirchner, e panelaço, em 2015 no Brasil, durante o governo de Dilma Rousseff, corroboraram o processo de expansão discursiva do populismo (LACLAU, 2013 [2005]), que desemboca no que vem sendo chamado contemporaneamente de populismo algorítmico (MALY, 2018, 2019) e populismo digital (CESARINO, 2018, 2019). Para tanto, examinaremos reportagens argentinas e brasileiras, disponibilizadas em sites jornalísticos, produzidas na época dos eventos mencionados, à luz da Análise do Discurso.

Partindo de uma perspectiva discursiva, entendemos que não existe discurso neutro, tampouco transparente. Assim, as noções de neutralidade e transparência são concebidas aí como estratégias enunciativas. Defendemos que o modo como cada jornal constrói enunciativamente as manifestações revela suas filiações sóciohistóricas, assim como seus posicionamentos ideológicos, atravessados por distintas e contraditórias formações discursivas (FOUCAULT, 2014 [1969]; SERRANI, 2010) que conduzem a determinados efeitos de sentido. Portanto, pretendemos neste artigo analisar comparativamente as materialidades linguístico-discursivas de determinadas construções jornalísticas no Brasil e na Argentina, sob a ótica dos estudos discursivos, em diálogo transdisciplinar com a reflexão laclauniana acerca 
do discurso populista, além dos teóricos acima mencionados, que estudam novas formas digitais do populismo.

Advogamos em favor de uma visão comparada, pois compreendemos que tal abordagem pode trazer luz sobre os funcionamentos discursivos de contextos sóciohistóricos distintos. Diante disto, consideramos que o cotejo entre materialidades linguísticas realizadas em "línguas próximas", como o português brasileiro e o espanhol argentino, promove a percepção tanto de associações comparativas quanto de diferenças discursivas substanciais, mobilizadas por diferentes esferas do discurso, como a jornalística, enfocada neste artigo. Deste modo, observamos que a incursão analítica entre textualidades pertencentes a distintas zonas linguísticonacionais permite-nos perceber que superfícies linguístico-semióticas aparentemente semelhantes "não necessariamente suportam intuições e interpretações idênticas" (FANJUL; GONZÁLEZ, 2014, p.11), atuando neste processo diversos fatores que atravessam as memórias discursivas que se erigem em cada contexto.

Sendo assim, a seguir apresentaremos nossa inserção teórica na Análise do Discurso e, a partir disto, discutiremos alguns aportes teóricos a respeito da noção de discurso jornalístico. Ato contínuo, contextualizaremos os movimentos conhecidos como cacerolazo e panelaço, para situarmos brevemente as condições de produção dos discursos nas conjunturas sócio-históricas argentina e brasileira. Abordaremos o conceito de discurso populista, com vistas a trazer à baila reflexões sobre esta questão, desenvolvidas por Ernesto Laclau (2013 [2005]), bem como seu avanço em direção às noções de populismo algorítmico (MALY, 2018, 2019) e populismo digital (CESARINO, 2018, 2019). Em seguida, passaremos às análises do corpus e, por último, teceremos nossas considerações finais.

\section{PERSPECTIVA DISCURSIVA}

A Análise do Discurso (AD) é uma perspectiva teórica que concebe o sentido como objeto sócio-histórico. Desta forma, a ideia de transparência da língua(gem) - vinculada ao atravessamento de efeitos imaginários que produzem a ilusão, por exemplo, de que o discurso jornalístico "retrata" a realidade - é rechaçada pelo dispositivo teórico da $\mathrm{AD}$. Além disso, não se pensa, a partir de uma perspectiva discursiva de análise, numa oposição rígida entre forma e conteúdo, preferindo-se conceber a ideia de "forma material" (CELADA; PAYER, 2016), que considera, simultaneamente, forma e conteúdo como materialidades linguístico-históricas, visto que entendidas como acontecimento linguístico em um sujeito atravessado pela história. 
Seguindo a esteira dessa colocação, é importante refletir, sob a ótica da $\mathrm{AD}$, sobre o modo como o sujeito é perpassado por formações ideológicas que estabelecem as condições do dizível em dada conjuntura sócio-histórica. As formações ideológicas compõem-se a partir de formações discursivas que, segundo Foucault (2014[1969]), possibilitam ao indivíduo constituir-se enquanto sujeito na ordem do simbólico. Deste modo, a materialização enunciativa que emerge a partir da instância de autoria dos textos jornalísticos, assim como de outras esferas do discurso, deve ser entendida, no escopo teórico da $\mathrm{AD}$, como posição discursiva, filiada a uma (ou mais) formações discursivas, inscritas em determinada formação ideológica.

\section{DISCURSO JORNALÍSTICO}

Concebemos - a partir de Dela-Silva (2012), Dela-Silva e Santos (2018) e Mariani (1996, 2001[1993]) - o discurso jornalístico como uma das manifestações do domínio midiático que pressupõe a geração de um efeito de evidência' de que sua atividade se destina a apenas fazer "um relato de fatos". O discurso jornalístico, entretanto, é enunciado a partir de uma dada posição discursiva e se caracteriza, desta maneira, enquanto gesto de interpretação que se assenta sob um imaginário já estabelecido. Sendo assim, o próprio processo de relatar e reportar fatos já desempenha certa determinação dos sentidos e se inscreve em dadas práticas discursivas marcadas sócio-historicamente (MARIANI, 1996).

Para Dela-Silva (2012, p.180), por exemplo, não é possível entender a mídia "como uma simples tecnologia voltada à comunicação", tampouco é plausível enxergar o jornalismo como mera atividade voltada para o fornecimento de informações. Desta maneira, o relato jornalístico produz-se enquanto evidência de objetividade e imparcialidade, como se fosse um retrato do real, o que se configura como forma de apagamento de seus processos de (re)construção discursiva, em que atuam estratégias de seleção, recorte e interdição. Mediante isto, a esfera jornalística projeta a ideia de que se dedica a relatar fatos que "falam por $\mathrm{si}^{\text {", }}$ encetando o apagamento do sujeito que opina e interpreta, o que contribui para as ilusões de transparência da linguagem e de objetividade jornalística. Para construir tal efeito

1. Segundo Mariani (2016, p. 43), as evidências discursivas atuam sob a regularização dos sentidos, gerando efeitos de "naturalidade" e "originalidade", ou seja, do "familiar" e do "evidente" (como "aquilo que só pode ser de tal maneira"), contribuindo assim para a naturalização da ideia de transparência. As evidências discursivas, deste modo, favorecem a produção de estereotipias, construções imaginárias e idealizações que se consolidam em determinada prática discursiva. 
de evidência, como se o jornalismo fosse constituído por uma espécie de língua "neutra", apagam-se também as condições de produção do discurso, bem como seus determinantes histórico-sociais. Concordamos com Mariani (1996, p.65) quando a estudiosa argumenta que

Fazendo crer que apresenta os fatos tais como são, com uma linguagem isenta de subjetividades, o discurso jornalístico (...) mascara (...) um apagamento da interpretação em nome dos fatos que falam por si. Trata-se de imprimir a imagem de uma atividade enunciativa que apenas mediatizaria - ou falaria sobre - da forma mais literal possível um mundo objetivo.

O discurso jornalístico, ao se vincular a redes de formações discursivas que perpassam discursos em circulação na mídia, tem como propriedade a repetibilidade dos sentidos, ou seja, um retorno ao mesmo espaço do dizer. Este movimento parafrástico colabora com a formação da memória discursiva, que torna possível os já-ditos que interpelam o sujeito. Os dizeres, no entanto, não atuam somente no nível da paráfrase, podendo também gerar novas vinculações, sofrendo deslizamentos de/nos sentidos, que acarretam o funcionamento da polissemia. É através desta relação entre paráfrase e polissemia que o discurso jornalístico vai gerando uma determinada memória do dizer:

O discurso jornalístico toma parte no processo histórico de seleção dos acontecimentos que serão recordados no futuro. E mais ainda: uma vez que ao selecionar está engendrando e fixando sentidos para estes acontecimentos, a imprensa acaba por constituir no discurso um modo (possível) de recordação do passado. (MARIANI, 2001, p.33)

Entendemos, portanto, que o discurso jornalístico instala estratégias de encenação da informação, criando lugares de circulação para os acontecimentos discursivos, que logicamente são sempre construídos. Destes mecanismos derivam evidências de neutralidade, objetividade, transparência, credibilidade, verdade, autenticidade e realidade, as quais se mostram mais ou menos válidas no âmbito deste registro, de acordo com a eficácia dos efeitos ilusórios construídos pelos veículos de comunicação.

\section{CACEROLAZO E PANELAÇO}

Os regimes ditatoriais que se instauraram na América Latina nas décadas de 1960 e 1970 contribuíram para o surgimento e fortalecimento de massivas mobilizações em favor da resistência democrática. Uma destas formas de mobilização é conhecida como cacerolazo (em português, panelaço), entendido como "a ação de bater panelas pública e coletivamente" (COLOMBO; MARTELLI, 2015, p. 2). 
Sendo assim, os cacerolazos ou panelaços, como são conhecidos no mundo hispânico e no Brasil, respectivamente, surgiram em meados de 1971 no Chile, vindo a se difundir logo depois pela América do Sul. De acordo com Betencourt (2014, p. 12),

[os panelaços] se configuram como ações coletivas que aglutinam múltiplas formas de expressão sonoras a favor das lutas de um povo. Em sua maioria, os participantes de tais ações se utilizam de diversos tipos de panelas e/ou utensílios domésticos para produzir um território rico e de alta intensidade e complexidade sonora. Estes encontros permitem colocar corpos em movimento e, assim, criar e possibilitar a efetuação de novos territórios que se dão nos deslocamentos destas forças e fluxos.

Na Argentina, há o insurgimento de cacerolazos também nos anos 1970, durante os governos militares, como símbolo de protesto contra o regime repressor. No começo dos anos 2000, no auge da crise política e econômica do governo De La Rúa, os cacerolazos simbolizavam as panelas vazias, diante da promulgação do corralito, que imputava o confisco dos depósitos bancários e limites à disponibilidade de saques das contas correntes e poupanças existentes nas instituições bancárias argentinas (COLOMBO; MARTELI, 2015). Durante a era kirchnerista (2007-2015), no segundo mandato de Cristina Kirchner, novos cacerolazos se fizeram presentes. Após mais de uma década da crise de 2001, as taxas de pobreza e de desemprego haviam sido reduzidas de forma considerável (LAPOLLA CANTONI, 2016). A inflação, no entanto, se elevou fortemente entre 2012 e 2013. Como uma das principais críticas ao governo, destaca-se o caráter confrontador de Cristina Kirchner, que travou conflitos com diversos setores, tais como a imprensa, os ruralistas e os sindicalistas. O kirchnerismo, assim, se confrontou, com três massivas mobilizações na forma de cacerolazos: o $13 \mathrm{~S}$ (ocorrido em 13 de setembro de 2012), o $8 \mathrm{~N}$ (em 08 de novembro de 2012) e o 18 A (em 18 de abril de 2013). Dentre as pautas reivindicadas, destacam-se enunciados contra a corrupção, a inflação, a insegurança, o projeto para modificar a constituição a fim de possibilitar nova reeleição da presidenta, dentre outras. Segundo cientistas sociais e políticos (GOLD, 2015; LAPOLLA CANTONI, 2016), a principal diferença entre as manifestações de 2001 e as de 2012/2013 se dá pela organização on-line de tais protestos. A partir disto, as manifestações são analisadas, por meio de inúmeras leituras, como: protestos de setores minoritários das classes média e alta que defendiam seus interesses; reivindicações construídas discursivamente como "antipolíticas", apoiadas em uma crise de representação dos cidadãos argentinos, cuja memória remonta ao cenário político de 2001, em que se instaurou "la incapacidad de los partidos políticos para captar las demandas de la gente" (GOLD, 2015, p. 198); manifestações opositoras, politizadas e organizadas, que estariam gerenciadas e dirigidas por líderes políticos 
através de redes sociais; ou numa perspectiva que se contrapõe à anterior, como movimentos espontâneos, apartidários, autoconvocados pelos cidadãos, ganhando o caráter de protestos "multitudinários".

No Brasil, os panelaços remontam às manifestações em prol da democracia, conhecidas como "Diretas Já", que ocorreram entre novembro de 1983 e abril de 1984, no processo conhecido como transição democrática. Na ocasião, a população protestou nas ruas, solicitando que o Congresso aprovasse a Emenda Dante de Oliveira, a fim de que houvesse eleições diretas para presidente da república. Em 1992, no cenário político de reivindicação pelo impeacbment do então presidente Fernando Collor de Mello, emergiu uma nova onda de panelaços devido às denúncias de corrupção. Cerca de 20 anos depois, em junho de 2013, novas mobilizações despontaram a partir da manifestação que ficou conhecida como "movimento passe livre", em resposta ao aumento de tarifa do transporte público. A partir deste evento, houve uma propagação de manifestações por todo o país, ampliando-se o leque para uma gama de pautas reivindicatórias. Antonio Negri, ao falar sobre as manifestações de 2013, afirma que a multidão

\begin{abstract}
se organiza em torno dos eventos do momento, nos quais uma linguagem comum se expressa. Uma linguagem comum que nasce da indignação e do protesto, do cansaço de sempre se encontrar em situações que não têm saída (...) Mas há um outro elemento que é a singularidade. Quando a multidão se move, nunca é simplesmente uma massa, é uma riqueza plural de elementos de questionamentos de vida. É claro que aqui nasce um problema de organização. Há um grande problema de unidade, de articulação dos movimentos, em meio a muitas singularidades. Mas esta é também a riqueza, a beleza do processo que vivemos. (NEGRI, 2014, n.p.)
\end{abstract}

Em março de 2015, a multidão retorna às ruas em uma nova série de panelaços. Em 08 de março de 2015, os panelaços marcam presença nas ruas, nas sacadas de prédios e no ambiente digital, durante um pronunciamento de Dilma Rousseff em cadeia nacional, transmitido pela televisão, rádio e internet, na ocasião do dia internacional da mulher, no qual a presidenta falou do combate à corrupção e à crise econômica. Após esta data, ocorreram duas grandes mobilizações em todo o país em 15 de março e 12 de abril de 2015. As manifestações de 2015 assumiram um componente expressamente político (GOHN, 2016), marcando uma polaridade descrita como PT x antiPT, vinculada aos que haviam votado e aos que não haviam votado na presidenta então recém-reeleita. Dentre as pautas e reivindicações, são enfatizados escândalos de corrupção (projetados a partir da Operação Lava Jato), envolvendo, sobretudo, empresas estatais como a Petrobras; o ajuste fiscal e econômico; e a inflação. Dentre os protestos contra o PT (Partido 
dos Trabalhadores), havia os que pediam o impeachment da presidenta e outros que pediam intervenção militar.

Para estudiosos das ciências políticas (COLOMBO; MARTELI, 2015; GOHN, 2016), a principal diferença entre os protestos de 1984, de 1992 e os contemporâneos (2013 e 2015) é a diversidade de reivindicações destes últimos, colocando em circulação uma multidão que enseja inúmeras bandeiras e palavras de ordem, além também da organização on-line dos movimentos. As manifestações contemporâneas são entendidas enquanto protagonizadas pela multidão, que é múltipla, heterogênea, difusa.

Diante do exposto, salientamos, portanto, que compreendemos os cacerolazos e panelaços como movimentos que se inscrevem na memória discursiva argentina e brasileira, respectivamente, filiando-se a distintas (e até contraditórias) formações discursivas, entendidas enquanto conjuntos de regras anônimas, históricas, que definem "em uma dada época e para uma determinada área social, econômica, geográfica ou linguística, as condições de exercício da função enunciativa" (FOUCAULT, 2014 [1969], p.144). Neste sentido, é importante frisar que, embora a priori tenham insurgido em contraposição a modelos de organização política de extração populista, devido às ancoragens históricas do governo kirchnerista na memória discursiva do "peronismo" no contexto argentino e do governo Dilma na memória do "lulismo" no contexto brasileiro, tais movimentos se apropriaram de uma estrutura de posicionamentos polarizante (PT vs. antiPT no Brasil; K vs. antiK na Argentina), a qual, em grande parte por meio da mediação do discurso jornalístico naquele momento, foi vinculada metonimicamente à dicotomia que antagoniza "povo" e "governo" (i.e., grupos que detêm a hegemonia do poder do Estado), dicotomia esta que possui forte ramificação nas discursividades que atravessam a noção de populismo.

\section{DISCURSO POPULISTA}

De acordo com Ernesto Laclau, o populismo, em lugar de ser pensado como uma ideologia política própria que representaria uma espécie de "anomalia" em relação à democracia representativa, pode ser visto enquanto "um modo de construir o político" (LACLAU, 2013[2005], p. 28). Para a constituição de seu funcionamento lógico, são engendrados certos padrões discursivos, dentre os quais elencamos alguns que nos interessam particularmente, a saber: a criação de polaridades e dicotomias; a criação de afetos; e a exaltação do espontâneo. 
Sendo assim, o discurso populista constrói a identidade de um povo, em meio a um amálgama de identidades coletivas. Esta identidade popular necessita estar em um eixo antagonístico, para assim configurar uma espécie de polaridade, calcada na figura de um povo supostamente unificado versus aquele que se opõe a ele, ou seja, "o inimigo". Esta construção de povo é substancialmente política, uma vez que tal categoria não é estática e se comporta como uma construção discursiva mobilizada por figurações homogeneizantes. Sendo assim, a lógica do populismo coloca em circulação uma identidade coletiva forjada discursivamente.

De acordo com Laclau (2013 [2005], p. 137), o discurso populista pode ser resumido da seguinte maneira:

\footnotetext{
Vimos até aqui que o populismo requer a divisão dicotômica da sociedade em dois campos - e um deles apresenta-se como uma parte que reivindica ser o todo; sabemos que essa dicotomia envolve a divisão antagônica do campo social: que o campo popular pressupõe, como condição de sua constituição, a construção de uma identidade global a partir da equivalência de uma pluralidade de demandas sociais.
}

Nossa argumentação é, pois, a de que a mídia jornalística ajudou a trazer à baila, no período dos cacerolazos/panelaços que focalizamos, esse arquétipo dicotômico do discurso populista, mesmo em um contexto de questionamento da liderança popular kirchnerista, no segundo mandato de Cristina Kirchner, e de certa vacância de liderança popular, após o governo Lula - vacância esta não preenchida pela figura de Dilma Rousseff. Tal processo se articula e retroalimenta pelo funcionamento das formas de populismo contemporâneas que emergiram, sobretudo, a partir do ambiente digital, as quais também ratificam a dinâmica discursiva do antagonismo entre a projeção unificadora da imagem de povo versus o inimigo: neste caso, governos de esquerda que, tanto no contexto argentino quanto no brasileiro, venceram sucessivas disputas eleitorais e vinham sendo performativamente "retratados" (e visibilizados) pelas principais corporações jornalísticas de ambos os países como os "responsáveis" pela corrupção endêmica das instituições.

É importante lembrar aqui que, para Laclau (2013[2005]), o fenômeno populista só pode se dar por meio da assunção da figura de um líder que retrospectivamente constitui - e é constituído - pela figura do povo. Esta compreensão basilar do populismo, predominante no séc. XX, vem sofrendo, contudo, modificações no contexto sociopolítico do séc. XXI. Com o advento da digitalização, o populismo se processa em meio a um agenciamento on-line. Sendo assim, em lugar de um líder carismático personificado, estas novas formas de populismo dão ensejo a um ativismo algorítmico (MALY, 2018, 2019), organizado virtualmente. Nesta configuração, as redes sociais desempenham o papel do líder 
ao disseminar enunciados que, estabelecendo e articulando demandas, contribuem para a fabricação da categoria povo.

O populismo algorítmico é entendido, assim, como uma relação discursiva mediatizada digitalmente. Isto significa conceber as mídias digitais não apenas como meros suportes ou canais que hospedam este populismo, mas sim mecanismos próprios que dispõem de algoritmos e recursos tecnológicos capazes de remodelar a linguagem populista.

Maly $(2018,2019)$ analisa esse novo fenômeno do populismo aludindo à campanha a favor de Donald Trump, em meio digital, no contexto da eleição presidencial norte-americana em 2016 - contexto este muito semelhante ao que se observou no âmbito das eleições brasileiras de 2018. O autor destaca três tipos de ativismo algorítmico, quais sejam: (1) o dos chamados clickfarms: pessoas contratadas para "curtir" e "compartilhar" conteúdos em redes sociais como Facebook e Twitter, contribuindo tanto para a construção de um discurso de apoio popular como para a ativação dos algoritmos das redes sociais, uma vez que quanto mais likes, shares e retweets os conteúdos atingem, mais eles são distribuídos a outros públicos em potencial ${ }_{i}(2)$ o das redes de robôs: dispositivos acionados nas discussões políticas virtuais, disseminados principalmente no Twitter, que servem para difundir conteúdos dos candidatos, com tweets carregados de mensagens que vão ao encontro de valores nutridos por diferentes grupos identitários, construindo assim, de modo artificial, o apoio popular; e (3) o de ativistas e celebridades midiáticas: que postam diariamente tweets, pedem retweets e levantam bashtags de apoio aos seus candidatos, além de estimularem o público a realizar atividades off-line para angariar votos, apropriandose muitas vezes da discursividade do populismo, ao mobilizarem, por exemplo, a dicotomia "povo versus elite".

Mediante tal cenário, podemos entender que o populismo algorítmico implica a mobilização do discurso dicotômico que constrói a imagem de soberania popular (de um povo unido) versus o inimigo. Tal discurso precisa se transformar em demandas capazes de unificar a categoria povo. Em âmbito digital, estas demandas se tornam concretas por meio da estratégia de datafication de pessoas, compreendida como uma operação de recolhimento de dados por meio de ferramentas tecnológicas, a fim de organizar um empreendimento orientado a partir de uma base de dados. Deste modo, assentado em demandas e alicerçado na infraestrutura da mídia digital, o conhecimento sobre o público é coletado, e o discurso populista é distribuído. Criando assim a ilusão discursiva de estar imbricada à própria voz de um candidato que vai sendo consecutivamente personificado e mitificado na figura de líder, a 
mídia digital constitui o povo e é constantemente constituída por ele na forma de likes, shares, retweets, comentários, followers, ativistas e eleitores.

A partir desse funcionamento, compreendemos que as mídias digitais não são apenas intermediárias que distribuem os conteúdos, mas também os alteram e (re)organizam, atuando sob uma agência algorítmica. No contexto do populismo algorítmico, é através da interação entre agentes humanos e não humanos, isto é, cidadãos, ativistas e algoritmos, que os discursos políticos são produzidos e replicados.

Maly (2018) ressalta que os algoritmos e as possibilidades gerais das mídias digitais estão delimitados por princípios neoliberais que se fundamentam na valorização da hierarquia, na concorrência e na mentalidade de que o "vencedor leva tudo". O princípio da popularidade, ligado a uma lógica de "quanto mais seguidores tem, mais valioso é", desempenha um relevante papel nas mídias digitais. A partir desta lógica, um discurso populista, para se reivindicar como a voz do povo, precisa alcançar muitos likes, shares, followers etc., a fim de desencadear a ativação dos algoritmos em direção a públicos potenciais cada vez maiores. No Twitter, por exemplo, a agência computacional materializa-se nos chamados trending topics (assuntos mais comentados), que organizam, por meio da seleção e priorização dos conteúdos, de maneira algorítmica, as atividades dos usuários tidas como "mais relevantes".

Cesarino (2018, 2019), ao analisar o cenário político das campanhas presidenciais brasileiras de 2018, observa que este novo tipo de populismo, entendido como populismo digital, fundamenta-se na relação entre política e mídias digitais. A autora analisa que o cenário do bolsonarismo, por exemplo, se aproveita da expansão considerável do ambiente dicotômico materializado no racha petismo $\mathrm{x}$ antipetismo, amplamente corroborado pelos jornais de grande circulação no país, tanto no período eleitoral de 2014, quando a presidenta Dilma foi reeleita, quanto no período dos panelaços contra sua gestão. A propagação dos efeitos imaginários deste racha foi, ainda segundo a pesquisadora, fator preponderante para a vitória de Jair Bolsonaro nas eleições de 2018.

De maneira análoga, podemos afirmar que, no cenário argentino, a oposição kirchneristas $\mathrm{x}$ antikirchneristas, performatizada por jornais de grande porte durante os cacerolazos, foi também fundamental para a ascensão de Macri. Seguindo a esteira desta reflexão, podemos perceber que os movimentos de cacerolazo/panelaço colocaram em circulação uma multidão que pôde ser, na especificidade sóciohistórica de cada zona linguístico-nacional, gradualmente transformada em "povo", por meio do agenciamento de visões políticas homogeneizadoras, promovido pelo 
discurso jornalístico e desdobrado em distintas performatividades em cena no populismo digital.

Finalizada essa parte de apresentação e discussão de aportes teóricos, passemos à seção de análise, em que examinaremos a interface entre construções textuais jornalísticas, discurso populista e mídias digitais.

\section{ANÁLISE}

O corpus de reportagens selecionado para este artigo engloba publicações de jornais argentinos e brasileiros disponibilizados em plataformas on-line. Constituímos assim uma espécie de arquivo composto por um conjunto de textos jornalísticos que abordam manifestações populares argentinas e brasileiras. A noção de arquivo, em sentido foucaultiano, pode ser compreendida como conjunto de discursos "efetivamente pronunciados" (CASTRO, 2016, p.43) que mantêm entre si uma relação, sendo, portanto, atravessados por regularidades. Cronologicamente, as reportagens abrangem, no contexto argentino, o intervalo entre o segundo semestre de 2012 e o primeiro de 2013. Já com relação ao contexto brasileiro, os textos se inscrevem no recorte temporal do primeiro semestre de 2015.

No que tange às condições de produção do contexto argentino, os fragmentos que exibimos adiante aludem às manifestações públicas ocorridas, no formato de cacerolazos, em 13 de setembro de 2012, 8 de novembro de 2012, 18 de abril de 2013 e 24 de abril de 2013. Dentre os principais motivos dos protestos elencados pelos jornais, destacam-se juros altos, inflação, reformas governamentais referentes à "democratização" da justiça imputadas pelo governo à época e escândalos de corrupção. Observemos, nas sequências discursivas² (doravante, SD) mostradas a seguir, manchetes e trechos de reportagens publicadas em periódicos on-line:

\section{(SD1): "Seguridad, libertad y justicia", los principales reclamos de la gente}

Con bombos, cacerolas y banderas, decenas de miles de personas protestaron en Plaza de Mayo en repudio a las estadísticas oficiales, la inseguridad, la re-relección y por la libertad de expresión.

Masiva protesta por las calles de Buenos Aires.

(Clarín, 14/09/12 - grifos nossos)

2. Podemos entender a noção de sequência discursiva como uma materialidade linguística inscrita em um determinado contexto sócio-histórico. As sequências discursivas são reguladas, na $\mathrm{AD}$, pelas condições de produção do discurso e, de acordo com Courtine (2016), derivam do procedimento metodológico de recorte do corpus a ser analisado. 
(SD2): "Estamos reclamando por la inseguridad y por la inflación que el Gobierno ni menciona", sostuvo uno de los manifestantes. "Acá no hay partidismo ni intereses. Este es el pueblo, el verdadero. El que quiere la verdad y que se cumplan las leyes y haya Justicia. Y que no nos mientan más", reclamó otra mujer.

(Clarín, 14/09/12 - grifos nossos)

\section{(SD3): Marchas, reclamos y acciones activan la participación social}

Las masivas movilizaciones de protesta, el rechazo a la reforma judicial y la indignación ante la corrupción encendieron a las clases medias urbanas. Riesgos y perspectivas de un fenómeno incipiente.

Contra la "democratización de la Justicia". El 24 de abril pasado, cientos de personas se manifestaron espontáneamente frente al Congreso, mientras los legisladores votaban.

(Clarín, 02/06/13 - grifos nossos)

(SD4): Cargados de banderas y presentes en cada acto en el que habla la Presidenta, miles de seguidores enrolados en distintos movimientos sociales o en la taquillera agrupación La Cámpora demuestran a diario que la militancia está viva y organizada entre los grupos afines al oficialismo. La novedad, en cambio, es un incipiente pero firme reverdecer de la participación social en sectores de clase media urbana: tan masivo como difuso y carente de liderazgos, el explosivo deseo de "hacer algo" para modificar un panorama que se vislumbra negativo igualó los reclamos por la inseguridad y la inflación con las quejas por la corrupción y el atropello al Poder Judicial.

(Clarín, 02/06/13 - grifos nossos)

Conforme podemos observar nas SD acima, as reportagens jornalísticas constroem, por meio de significantes como "la gente" e "el pueblo", uma manifestação centralizada essencialmente na figura de um "povo" que estaria unificado. De acordo com a reflexão desenvolvida por Laclau (2013 [2005]), podemos detectar no populismo uma espécie de "razão" em que se desvelam algumas "fórmulas". Estas "fórmulas" engendram certos padrões discursivos que contribuem para construir um dado cenário político. Nas narrativas jornalísticas capturadas por meio das SD selecionadas, é possível verificar, neste sentido, uma vontade de homogeneizar as "decenas de miles de personas" que estavam protestando, para que, adquirindo o rótulo de "povo", suas diversificadas demandas fossem articuladas, de modo que uma em particular passasse a assumir o papel de demanda hegemônica ${ }^{3}$, representando assim o discurso popular como um todo.

3. "Demanda social" e "hegemonia" são também conceitos desenvolvidos por Laclau (2013 [2005]). De acordo com sua perspectiva, uma demanda social seria uma unidade mínima a se levar em 
Como já dissemos, o discurso populista lança mão de discursividades pautadas em dicotomias e polaridades. Temos assim: o povo versus o inimigo. Nas $\mathrm{SD}$ anteriores, tal dicotomia se materializa na seguinte relação: povo vs. governo institucionalizado. No enunciado destacado em negrito na SD2, por exemplo, visualizamos: "Acá no hay partidismo ni intereses. Este es el pueblo, el verdadero". Podemos entender que tal enunciado expressa uma máxima do discurso populista. Há a presença de um povo, caracterizado sempre de maneira vaga e indeterminada, estratégia constitutiva da lógica populista. Este povo, que é "verdadeiro", se reuniu de maneira "espontânea", realizando uma autorrepresentação, sem se vincular (diretamente) a partidos políticos, o que cria o efeito de evidência de ser uma manifestação "sem interesses partidários". Além disso, o mecanismo de negação da ideia de "corrupção" aparece como demanda que unificaria todos os manifestantes, funcionando como a demanda hegemônica que representaria o interesse popular.

Diante disso, as manifestações são descritas, em muitas matérias, como protagonizadas pelas "clases medias urbanas", correlacionadas aí à figuração de povo, como se pode observar na SD3. Longe de ser uma categoria estática, "povo" é uma construção discursiva que visa a representar uma demanda hegemônica. Este efeito homogeneizante é conseguido por formulações evasivas que caracterizam a massa de manifestantes que aderem a tais protestos como "carente de liderazgos", conforme se vê por exemplo na SD4. Nestes enunciados, não são apontados nomes de líderes dos movimentos, de forma a apagar marcas discursivas ou especificações que possam conduzir a identidades singulares. A heterogeneidade deste espaço social (configurado pelas manifestações) se homogeneíza por meio de significantes vazios que criam o efeito de indeterminação. Neste discurso de natureza populista, o relevante é que sejam salientadas as identidades coletivas, a fim de que estas possam determinar a relação entre o povo e o seu inimigo.

Vejamos agora o contexto brasileiro. Com relação às condições de produção do discurso, os textos jornalísticos abordam as manifestações públicas ocorridas em forma de panelaço nas datas de 08 de março, 15 de março e 12 de abril de 2015. Nestas manifestações, a população protestou contra o governo da então presidenta Dilma Rousseff. Dentre os principais motivos dos protestos, destacam-se a inflação

consideração a fim de que haja uma experiência política populista. Em outras palavras, como nos exemplos das análises em questão, uma demanda pode se referir a uma reivindicação. Sendo assim, o povo se constitui por meio da articulação de uma pluralidade de demandas. Já a hegemonia consiste na elevação de uma diferença particular à representação de um todo, de forma incomensurável. Desta maneira, uma demanda hegemônica é aquela que, dentre o conjunto de demandas articuladas, passa a representar o discurso popular, comportando-se como um ponto unificador entre todas as demandas e assumindo um valor de inestimável importância em relação às outras. Em suma, a relação de uma demanda hegemônica frente às demais é de uma parte que passa a identificar o todo. 
alta, a crise econômica e os escândalos de corrupção (relacionados à Operação Lava Jato). Observemos algumas sequências discursivas elencadas a seguir:

\section{(SD5): Indignação com a corrupção foi motivação para maioria nas ruas}

Cerca de 543 mil foram às ruas em 24 capitais e no Distrito Federal, segundo a Polícia Militar; São Paulo reuniu 100 mil na av. Paulista, aponta o Datafolha

(Folha de S. Paulo, 15/03/2015 - grifos nossos)

\section{(SD6): Irritação com corrupção foi motivação para maioria}

O impeachment da presidente Dilma Rousseff conta com o apoio de 77\% das 100 mil pessoas que estiveram neste domingo (12) na avenida Paulista, mas nem metade deles acha que ela seria afastada. É o que mostra a pesquisa Datafolha realizada durante a manifestação. Ainda assim, só $13 \%$ dos manifestantes saíram de casa com a intenção de pedir o impeachment da presidente. $\mathrm{O}$ motivo mais citado por eles para ir à Paulista foi indignação com a corrupção, apontado por 33\% dos entrevistados. Um em cada dez pessoas estava lá para protestar contra o PT (...) Moradoras da Vila Carrão, na Zona Leste, pegaram ônibus e metrô para participar do protesto. "Sou eleitora, quero continuar votando e para isso é preciso limpar a política", diz Maria Luiza.

(Folha de S. Paulo, 13/04/2015 - grifos nossos)

(SD7): Quase $80 \%$ dos manifestantes têm ensino superior, 35\% trabalham com carteira assinada e $41 \%$ ganham acima de 10 salários-mínimos. No segundo turno da última eleição presidencial, 83\% declaram ter votado em Aécio Neves (PSDB) e só 3\% em Dilma. Apesar disso, $95 \%$ afirmaram não serem filiados a nenhum partido.

(Folha de S. Paulo, 13/04/2015 - grifos nossos)

\section{(SD8): Manifestantes também atacam a oposição em ato contra governo em SP}

Os movimentos que foram às ruas em São Paulo neste domingo (12) contra o governo da presidente Dilma Rousseff (PT) fizeram também duras críticas à oposição, principalmente ao PSDB e ao senador Aécio Neves (MG), segundo colocado na disputa pelo Palácio do Planalto em 2014

(Folha de S. Paulo, 12/04/2015 - grifos nossos)

Conforme podemos examinar nas SD acima, a demanda enunciada como "indignação com a corrupção" (SD5 e SD6) é eleita pelas construções jornalísticas como a hegemônica das manifestações, para assim projetar a imagem de manifestações protagonizadas por um povo que protesta contra seu inimigo, materializando a noção de fronteira antagônica. Tal demanda hegemônica (contra 
a corrupção), em termos laclaunianos, pode ser entendida como um discurso consensual, enfatizado pelas construções jornalísticas. Sendo assim, apesar de as matérias enfocadas delinearem um perfil de pessoas pertencentes à classe média ("Quase 80\% dos manifestantes têm ensino superior, 35\% trabalham com carteira assinada e $41 \%$ ganham acima de 10 salários-mínimos", conforme podemos visualizar na SD7), esta parcela da sociedade é construída discursivamente como a representação da sociedade como um todo. Deste modo, a construção jornalística corrobora a lógica populista de um "povo" unido contra o "governo (corrupto)". Assim, as narrativas jornalísticas relatam cidadãos comuns, identificados por seus nomes e bairros (como na SD6), reforçando a dicotomia povo versus corrupção, sem enfatizar a heterogeneidade dos grupos sociais que se apresentam como manifestantes. Nesta construção discursiva, o povo é "apartidário" e, por isso, também ataca a oposição, como na SD7 e na SD8.

Note-se, assim, que as reportagens do Clarín e da Folha de S. Paulo em versões on-line que selecionamos para a composição de nosso corpus, conforme se pôde observar nos exemplos anteriores, costumam (re)criar narrativas acerca das manifestações, exaltando geralmente o caráter espontâneo e apartidário destas, descrevendo os personagens protestantes e desenvolvendo um discurso populista calcado na dicotomia povo versus governo (inimigo). A seguir, exibimos outras sequências discursivas, desta vez, do periódico argentino La Nación e do brasileiro O Globo. Tais jornais também corroboram o processo de expansão discursiva do populismo, de acordo com a visão de Laclau (2013 [2005]). Contudo, nestas construções jornalísticas, em lugar de se focalizar em primeiro plano o povo e as manifestações, são ressaltadas falas de políticos governistas e não governistas em relação aos protestos. Vejamos as SD a seguir, provenientes destes jornais:

\section{(SD9): Cristina Kirchner criticó la protesta del 18A contra la reforma judicial}

"Los que estaban en contra de las 6 leyes de reforma judicial que enviamos al Congreso. De las 6. Qué raro. ¿Ni una sola les gusta?", escribió en Twitter

(La Nación, 27/04/13 - grifo nosso)

(SD10): Para el kirchnerismo "hubo menos gente"

El diputado provincial Fernando Navarro fue uno de los pocos oficialistas que hablaron sobre el cacerolazo; insistió con la tesis de que fue una protesta opositora

(La Nación, 19/04/13 - grifos nossos) 
(SD11): PT diz que panelaço fracassou e foi 'financiado' por partidos de oposição

$\mathrm{Na}$ noite de domingo, enquanto presidente apelava por coragem para enfrentar corrupção, moradores de três estados e do DF fizeram protestos

(O Globo, 09/03/15 - grifos nossos)

\section{(SD12): Aécio diz que PT tenta 'tapar o sol com a peneira' ao acusar oposição de responsabilidade pelos protestos}

Para o senador, manifestações não defendem o terceiro turno e são reação de setores que se sentem enganados

BRASÍLIA - O presidente nacional do PSDB, senador Aécio Neves (MG), reagiu na noite desta terça-feira às acusações da presidente Dilma Rousseff de que a oposição quer um terceiro turno eleitoral. Aécio disse, em nota e nas redes sociais, que o PT tenta passar para a oposição a responsabilidade pelas manifestações críticas ao governo, que são feitas por setores da sociedade que se sentem "enganados". O tucano disse que as manifestações de ruas e nas próprias redes sociais "não defendem um terceiro turno", mas são "espontâneas e democráticas". "O PT continua tentando" tapar o sol com a peneira ao tentar responsabilizar a oposição pelas repetidas, e cada vez mais frequentes, manifestações críticas ao governo. As manifestações que ocorrem nas redes sociais, nos panelaços e nas ruas não defendem um terceiro turno. "São manifestações espontâneas e democráticas. Queremos um país em que todos tenham o direito de expressar sua opinião", disse Aécio, acrescentando: "São manifestações que nascem de forma espontânea em diversos setores da sociedade que se sentem enganados."

(O Globo, 09/03/15 - grifos nossos)

Nas SD selecionadas anteriormente, podemos observar regularidades enunciativas que dialogam com a polaridade "povo versus governo (inimigo)" do discurso populista. No contexto argentino, notamos que o periódico La Nación seleciona como manchetes de suas reportagens as opiniões de políticos kirchneristas com críticas às manifestações - opiniões que acabam por minimizar os protestos, diminuindo sua relevância (SD9 e SD10). Estes atores políticos ora atribuem tais manifestações à classe média, ora as apresentam como arquitetadas pela oposição.

No contexto brasileiro, também podemos observar este tipo de formulação enunciativa por meio da SD1 1 e da SD12. Nas construções jornalísticas de O Globo, podemos ver que na SD11, por exemplo, se seleciona como manchete a opinião do PT (Partido dos Trabalhadores) com relação às manifestações, ressaltando 
que são arquitetadas pela oposição. Já na SD12 podemos notar uma manchete que se configura como uma atitude responsiva do principal líder da oposição no cenário político daquele momento, o então senador Aécio Neves, em relação ao PT, ao negar que os protestos tenham sido arquitetados pela oposição. Ainda na SD12, o corpo da reportagem enfatiza a fala do senador, na qual se pode observar certa ressonância dos significantes "espontâneas", "democráticas" e "enganados", que conduzem a um efeito de sentido de manifestações apartidárias, isto é, sem cooptação política, e portanto espontâneas, realizadas por setores da sociedade que se sentiriam "enganados" e que, por isso, se filiariam ao discurso populista de povo (enganado) contra o governo (enganador, corrupto). Toda esta rede metonímica teleológica que se encadeia no nível enunciativo conduz à defesa da ideia de que tais setores teriam o direito de protestar e expressar sua opinião de forma livre, uma vez que as manifestações são asseguradas pela democracia.

Por fim, destacamos ainda construções jornalísticas que remetem à presença ou ausência de políticos de oposição nas manifestações. Observemos as SD seguintes:

\section{(SD13): Macri y el 18A: "Estoy del lado correcto"}

El jefe de gobierno porteño explicó las razones de su ausencia en la marcha, que calificó como "la más grande de la historia"

El jefe de gobierno porteño, Mauricio Macri, explicó las razones de su ausencia en la multitudinaria protesta de ayer en Buenos Aires y confió en los efectos que el cacerolazo tendrá de cara a las elecciones legislativas de octubre. "Fue la marcha más grande de la historia", señaló. En diálogo con radio Metro, el líder del Pro dijo que le dio libertad a los miembros de su partido para que hagan lo que quieran, pero que prefirió no asistir personalmente a la manifestación."Si yo iba a participar, era apropiarme de algo que yo no convoqué. Esto lo convocó espontáneamente la gente. Yo los alenté para que vayan", sostuvo.

(La Nación, 19/04/13)

\section{(SD14): Eduardo e Jair Bolsonaro fazem 'selfies' e distribuem abraços em SP}

O deputado federal Eduardo Bolsonaro (PSCSP) e o pai, o também deputado Jair Bolsonaro (PPRJ), foram tratados como celebridades durante a manifestação deste domingo (12), em São Paulo. Uma fila para 'selfies' e abraços ao lado de pai e filho foi formada em frente ao carro de som do grupo Revoltados Online. "Nós temos orgulho de dizer que somos deputados federais e podemos sair nas ruas para estar com o povo cara a cara. Quem não deve não teme", afirmou Eduardo Bolsonaro.

(Folha de S. Paulo, 12/04/15) 
As sequências acima dão visibilidade a falas de políticos da oposição - o então prefeito de Buenos Aires, Mauricio Macri, e o então deputado federal, Jair Bolsonaro - que em meio ao cenário de polarização política deflagrado pelas manifestações ascenderiam ao cargo de presidente da república, algum tempo depois, representando assim vitórias eleitorais do antikirchnerismo e do antipetismo, respectivamente. Percebemos que na SD13, no contexto argentino, Macri parece não querer encarnar completamente a figura do líder de caráter populista, ao decidir se ausentar fisicamente das manifestações, delegando protagonismo "a la gente", isto é, ao povo que "espontáneamente" as convocou. Contudo, o político também estimula a adesão a estes protestos por meio de estratégias de mobilização digital. Já na SD14, que concerne ao contexto brasileiro, por sua vez, Bolsonaro, junto com um de seus filhos, não só comparece à manifestação fisicamente, como também distribui "selfies" e "abraços" entre os manifestantes, filiando-se à prática discursiva populista que identifica figuras de líderes carismáticos ao status de celebridades que gozam de popularidade. Estes diferentes funcionamentos discursivos, no que tange à construção do líder, em um contexto e outro, sinalizam-nos que, na Argentina, a oposição antikirchnerista, apesar da vitória nas eleições de 2015, não parece ter seguido o caminho de performatização da figura de um líder capaz de suplantar o enraizamento do kirchnerismo na memória do populismo argentino. Já no contexto brasileiro, o governo Dilma parece ter sido atravessado pela memória do lulismo, marcado pela figura carismática e popular de líder do ex-presidente Lula. Esta ausência de líder deixada pelo lulismo vai desembocar na emergência do bolsonarismo, que, aproveitando o clima de antipetismo, desponta como um populismo de direita, fundamentado no populismo digital. Conforme sinaliza Cesarino (2018), o bolsonarismo configura uma forma de populismo digital na medida em que o líder ausente fisicamente (sobretudo nos debates presenciais das campanhas presidenciais de 2018) dá lugar ao líder construído e presente digitalmente, em meio à atuação do agenciamento algorítmico.

Diante do exposto, exibimos adiante uma tabela que resume as principais regularidades discursivo-enunciativas manifestadas nos segmentos verbais dos textos jornalísticos que compõem nosso corpus: 


\begin{tabular}{|c|c|c|c|}
\hline \multirow{2}{*}{\multicolumn{2}{|c|}{$\begin{array}{l}\text { - Foco no governo, com crítica direta, selecionando } \\
\text { suas falas e apontando suas contradições, } \\
\text { ofertando falas da oposição e recriando as } \\
\text { manifestações em } 2^{\circ} \text { plano, geralmente como } \\
\text { eventos espontâneos e apartidários. }\end{array}$}} & Argentina & Brasil \\
\hline & & La Nación & O Globo \\
\hline - & $\begin{array}{l}\text { Foco na cobertura das manifestações, realizando } \\
\text { narrativas destes movimentos e colocando-se ao } \\
\text { lado delas. }\end{array}$ & Clarín & Folha de S. Paulo \\
\hline
\end{tabular}

Ponderamos que essa expansão discursiva do populismo, por meio do funcionamento digital de veículos midiáticos vinculados a grandes corporações, favorecida por construções jornalísticas difundidas hoje mais através da internet do que pelo suporte impresso, desemboca nos novos fenômenos designados como populismo algorítmico (MALY, 2018, 2019) e populismo digital (CESARINO, 2018, 2019). Deste modo, tanto os cacerolazos argentinos de 2012/2013 quanto os panelaços brasileiros de 2015 contaram com um forte agenciamento em ambiente on-line e com convocações realizadas pelas redes sociais. Neste sentido, a categoria povo que se manifesta aí é constituída em meio ao ativismo algorítmico das mídias digitais, que, ao não personificar a figura do líder populista, cria a ilusão de que não existe mais intermediação, gerando um efeito de sentido de manifestações espontâneas e autoconvocadas pelo povo. Nesta configuração de populismo digital, a figura do líder populista encontra-se, assim, diluída e dispersa no ambiente virtual, fazendo com que o ativismo algorítmico desempenhe o papel de líder. Neste sentido, as mídias digitais constituem o povo e são constituídas por ele, na forma de likes, shares, retweets, comentários e followers.

A propósito dessa correlação entre discurso jornalístico e ambiente digital, observemos, a título de exemplo, outras materialidades semióticas que constituem nosso corpus, tais como as figuras abaixo, que constam de galerias de fotos que acompanham reportagens da edição digital do jornal La Nación: 




Figura 1. La Nación, 18 de abril de 2013

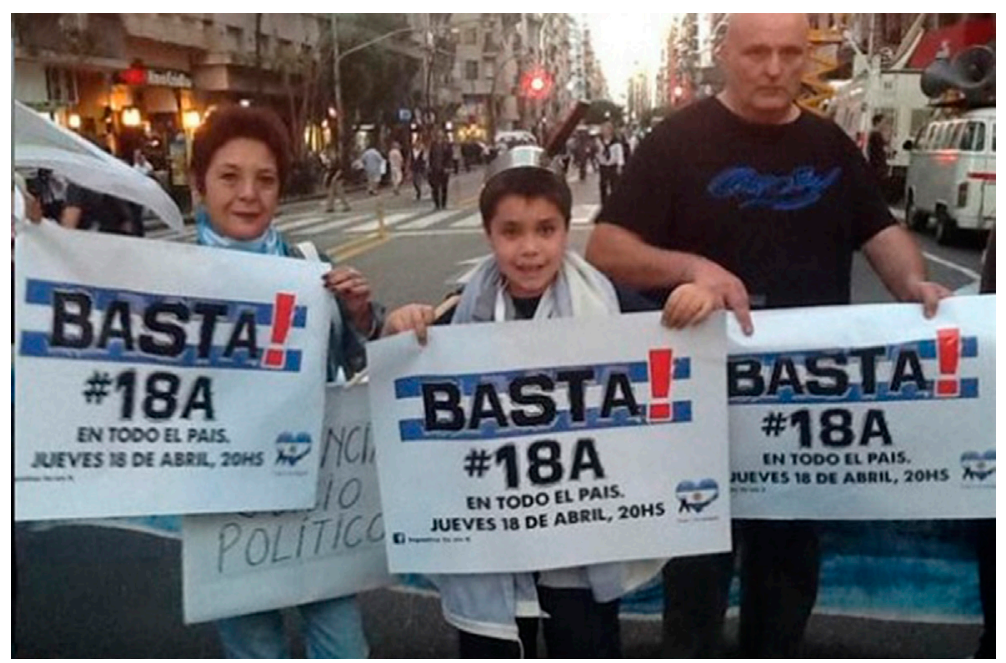

Figura 2. La Nación, 18 de abril de 2013

No contexto argentino, grupos organizados, como Argentinos Indignados, convocaram, através de seus sites e redes sociais, as manifestações por meio de formulações, tais como "Hagamos ruido" e "Digamos basta". Além disso, as datas dos eventos (13 de setembro, 8 de novembro e 18 de abril) transformaram-se em siglas que se converteram em hashtags (\#13S; \#8N $\# 18 \mathrm{~A})$ em plataformas virtuais como o Twitter. Nas imagens acima, podemos observar a relação de confluência entre os âmbitos on-line e off-line, uma vez que os cartazes materializam 
as formulações enunciativas "\#18A", sinalizando o relevante papel das mídias digitais no que tange à convocação das manifestações de rua. Não à toa, também, os textos jornalísticos tanto do Clarín quanto de La Nación aparecem vinculados a um conjunto de palavras-chaves, tais como "cacerolazo", "18A", "política", "redes sociales", "movilización", "protesta", "Cristina Kirchner", "gobierno", "Plaza de Mayo", "avance sobre la Justicia", "despertar cívico", "oposición", "protesta contra el gobierno", "provincias", "marcha a Plaza de Mayo", dentre outras, que funcionam como bashtags nos sites jornalísticos, relacionando o contexto sociopolítico das manifestações ao âmbito digital das redes sociais, bem como dando pistas do ativismo algorítmico destes movimentos, uma vez que tais palavras-chave ilustram os assuntos mais buscados.

Consideremos ainda, a modo de exemplificação, as imagens seguintes, incluídas também pela Folha de S. Paulo em galerias de fotos que acompanham suas reportagens on-line:

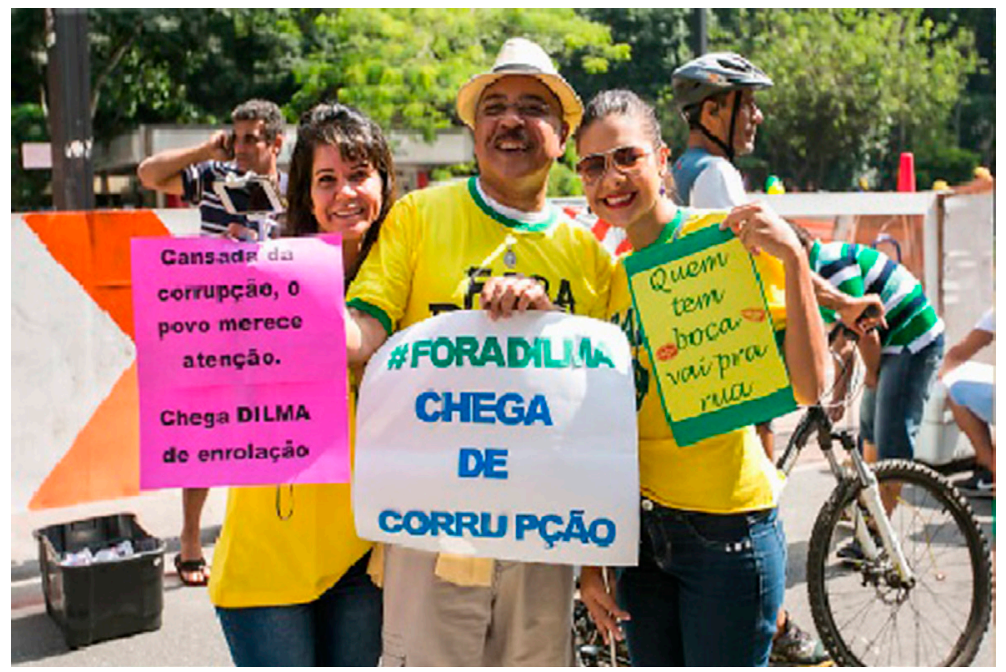

Figura 3. Folha de S. Paulo, 13 de abril de 2015 


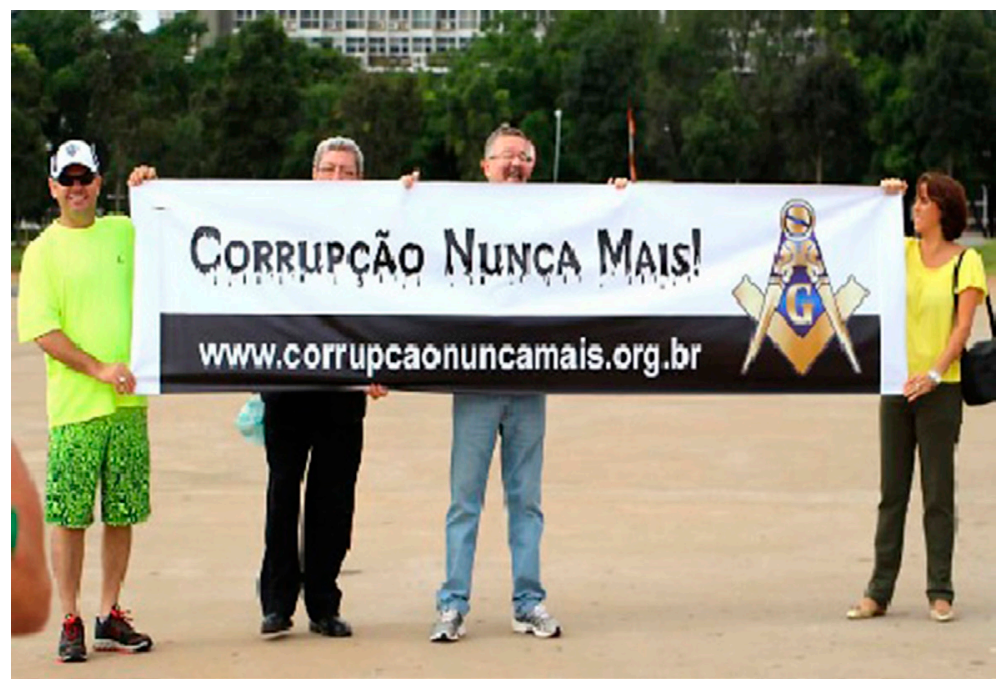

Figura 4. Folha de S. Paulo, 15 de março de 2015

Com relação ao contexto brasileiro, conforme podemos observar nas imagens acima, o enunciado "\#ForaDilma", ao se materializar como uma hashtag, também evidencia a influência das mídias digitais no agenciamento das manifestações. A faixa com o enunciado "Corrupção nunca mais" chega a exibir o endereço eletrônico do site do movimento. Nas manifestações brasileiras, grupos organizados, tais como Movimento Brasil Livre (MBL) e Vem Pra Rua, também realizaram uma forte convocação por meio de suas páginas no Facebook. O Vem Pra Rua chegou a realizar convocações para as manifestações de março e abril de 2015 através da publicação de vídeos na plataforma YouTube. Em 8 de março de 2015, durante um pronunciamento televisivo, radiofônico e pela internet em cadeia nacional, por ocasião do dia internacional da mulher, a então presidenta Dilma Rousseff falou do combate à corrupção e à crise econômica. O pronunciamento foi recebido com panelaços nas ruas, varandas de prédios e redes sociais. Tais panelaços haviam sidos organizados e disseminados por meio de mensagens em aplicativos como o WhatsApp, onde se pediam "panelaços", "buzinaços" e "vaiaços" durante o pronunciamento da presidenta. Nas redes sociais, estes manifestantes difundiram bashtags como \#Panelas NaJanela. Como atitude responsiva, apoiadores do governo realizaram um "tuitaço" por meio da bashtag \#DilmaDaMulher, em um claro trocadilho com a data do dia internacional da mulher, que foi a escolhida para o pronunciamento em cadeia nacional. Nas mobilizações de rua de 12 de abril, apoiadores do PT realizaram um novo "tuitaço" a favor da presidenta com a bashtag 
\#AceitaDilmaVez, entrando nos chamados trending topics. Instantaneamente, como uma marca do ambiente digital, protestantes e adeptos de movimentos contrários à presidenta, em resposta, subiram a bashtag \#SaiDilmaVez, materializando a polaridade discursiva PT $\mathrm{x}$ antiPT, enquanto marca desse jogo populista na esfera do virtual.

Dessa maneira, o populismo digital, por meio do ativismo algorítmico, propagase de forma acelerada pelas redes sociais, caracterizando-se pela indeterminação, pelo anonimato, pela vagueza e pela ausência de um líder corporificado fisicamente, cujo papel é desempenhado pelas mídias digitais. Conforme salienta Cesarino (2019), o populismo digital, por meio de estratégias de recursividade e replicação, faz circular um pensamento, ligado a uma epistemologia neoliberal, de que a intermediação não é mais necessária. Sendo assim, qualquer indivíduo, em qualquer lugar, conectado a alguma mídia social (como as mais difundidas: Twitter, WhatsApp, Facebook, YouTube, Instagram etc.), pode se apropriar destes padrões discursivos e reproduzi-los direta e instantaneamente. No entanto, esta crença de uma ausência de intermediação configura-se enquanto uma ilusão, uma vez que esta forma de populismo digital é pensada como uma relação discursiva mediatizada digitalmente não apenas por políticos e jornalistas, mas também por cidadãos comuns, por ativistas e pela agência computacional (MALY, 2018, 2019).

Os enunciados jornalísticos analisados anteriormente, seja em sua materialidade verbal, seja em sua materialidade verbo-visual (como a que se vê nas fotografias presentes em galerias de imagens que costumam, hoje em dia, acompanhar as publicações das matérias nos sites jornalísticos), atuaram em simultaneidade, como pudemos perceber, à ação do ativismo algorítmico, configurando imbricações discursivas que resultaram no movimento de expansão do populismo digital. Neste processo discursivo, a mídia jornalística mobiliza a noção laclauniana de fronteira antagônica, como estratégia própria da arquitetura textual do populismo, que determina a divisão dicotômica da sociedade em dois campos. Isto se materializa na polarização kirchnerismo versus antikirchnerismo e petismo versus antipetismo. Desta forma, percebemos que o discurso jornalístico, no bojo das disputas em cena no âmbito dos cacerolazos/panelaços, assumiu majoritariamente uma posição contrária aos governos, colocando-se assim ao lado dos grupos que reivindicam ser o todo. Tal posicionamento demonstra a adesão dos jornais ao chamado "campo popular", vinculado, conforme aponta Laclau (2013[2005], p. 137), à configuração de uma síntese identitária totalizante a partir do entrecruzamento de uma variedade de demandas. Sem a presença de um líder personificado, nesse momento enfocado pelas matérias jornalísticas que destacamos, o povo constituído em meio tanto ao 
agenciamento dos veículos de imprensa quanto do ativismo algorítmico sai às ruas portando símbolos nacionais, vestindo as cores da bandeira e manifestando uma suposta "soberania popular", conformando a construção discursiva de manifestações autoconvocadas e espontâneas.

Entendemos que o discurso populista é, portanto, um processo político que engendra a criação de polaridades e afetos, exaltando o espontâneo e o inespecífico. O funcionamento deste discurso traz em si uma perigosa intencionalidade de homogeneização do espaço social cuja consequência mais nefasta é a tentativa de silenciamento repressivo das vozes dissonantes, visto que constrói uma imagem de povo como amálgama de identidades imbuído de uma demanda dita "consensual" que se apresenta a priori como contrária ao poder, mas que se liga, ao fim e ao cabo, a muitas forças ideológicas e discursividades de caráter hegemônico.

\section{CONSIDERAÇÕES FINAIS}

O objetivo deste artigo foi promover uma reflexão acerca da maneira como as construções jornalísticas, ao recriarem as manifestações referentes ao cacerolazo argentino (2012/2013) e ao panelaço brasileiro (2015), corroboraram o processo de proliferação discursiva do populismo digital. Através da análise discursiva, em diálogo com os aportes teóricos de Laclau (2013[2005]), Maly $(2018,2019)$ e Cesarino $(2018,2019)$, pudemos observar que as mídias jornalísticas, ao construírem abordagens populistas dos cacerolazos/panelaços, colocaram em circulação a figura de um povo unificado versus um governo inimigo. Esta lógica do pensamento populista, disseminada no ambiente digital, ganhou efeitos expressivos que terminaram por conduzir, no contexto argentino, à derrocada do kirchnerismo, representada naquele momento pela vitória eleitoral de Mauricio Macri, em 2015, e no contexto brasileiro, ao impeachment de Dilma Rousseff, em 2016, e à ascensão do bolsonarismo, dois anos depois.

$\mathrm{Na}$ América do Sul, dicções populistas da história recente estiveram ligadas à ascensão democrática de governos de esquerda, como o kirchnerismo na Argentina e o lulismo no Brasil. No entanto, o fenômeno do populismo, para além de ser contemplado como tão somente filiado a uma dada ideologia, deve ser pensado, mais amplamente, como um agenciamento coletivo de enunciação que engendra processos de (re)construção do político, vinculados a determinados padrões discursivos que atravessam tanto as mídias jornalísticas quanto as novas formas de ativismo algorítmico. Com base neste pensamento, podemos concordar que o discurso populista pode se filiar a diferentes formações discursivas, como a 
da direita neoliberal, observada no cenário argentino do macrismo, e da extremadireita neoliberal, observada no cenário brasileiro do bolsonarismo.

No caso brasileiro, é possível afirmar, a partir do percurso de nossa reflexão, que o antagonismo PT $\mathrm{x}$ antiPT, difundido pelos jornais de grande circulação, no período pré-eleitoral, desdobrou-se durante a campanha presidencial de 2018 no clima de forte polarização entre eleitores de Bolsonaro versus eleitores de Fernando Haddad. Mobilizando cadeias essencialmente populistas, o discurso bolsonarista construiu sua campanha apropriando-se da metonímia "antipetismo" / "anticorrupção", somada ao reaproveitamento do imaginário patriótico (vide as cores verde e amarela terem virado símbolo dos bolsonaristas), bem como à construção de um líder "espontâneo" (que faz lives nas redes sociais em situações construidamente domésticas) e avesso ao dito "politicamente correto". A partir desta conjuntura, entra em ação o que se comporta como a especificidade do populismo digital: a evidência discursiva (MARIANI, 2016) da ausência de intermediação. Assim, o populismo digital produz a ilusão de que não se necessita mais de intermediação (política, institucional ou jornalística) entre o líder e o povo. Este processo de naturalização dos sentidos é possibilitado devido à arquitetura própria das plataformas digitais.

Contudo, é interessante notar que, no caso argentino, embora o período Macri tenha emergido em meio ao crescimento do discurso antikirchnerista, ao que parece o movimento tensivo dessa fronteira antagônica ressignificou aí a figuração discursiva de povo, projetando assim uma outra concepção de "inimigo" comum. Tal processo, a nosso ver, levou à derrota de Macri em sua campanha de reeleição e ao retorno do kirchnerismo ao poder com a vitória em 2019 da chapa formada por Alberto Fernández (presidente) e Cristina Kirchner (vice-presidenta). Isto demonstra uma possibilidade de ressignificações dinâmicas em direção a distintos posicionamentos ideológicos e discursivos no âmbito das estratégias de mediação acionadas pelo ativismo algorítmico.

Cabe-nos ainda sinalizar uma questão curiosa relacionada ao caso brasileiro, visto que, no momento atual, o acirramento das práticas discursivas do bolsonarismo, calcadas no populismo digital e na impressão de ausência de intermediação entre líder e povo, vem conduzindo grande parte das corporações de imprensa no Brasil a se posicionar contrariamente ao governo Bolsonaro. Isto indicia, na nossa opinião, que o jornalismo contemporâneo se encontra numa posição dilemática, tendo em vista o fato de ter corroborado a criação das condições de produção desse discurso dicotômico populista, conforme demonstramos, e de estar sofrendo, simultaneamente, um violento processo de deslegitimação social (insuflado 
inclusive por ataques diretos dos bolsonaristas à imprensa), processo este, todavia, engendrado por uma atmosfera política que o próprio discurso jornalístico ajudou a promover.

\section{REFERÊNCIAS}

BETENCOURT, P. R. (2014). Memórias dos cacerolazos: cartografia de forças não sonoras se tornando sonoras. Dissertação de Mestrado. Pós-Graduação em Mudança Social e Participação Política da Escola de Artes, Ciências e Humanidades da Universidade de São Paulo.

CASTRO, E. (2016). Vocabulário de Foucault: um percurso pelos seus temas, conceitos e autores. Belo Horizonte: Autêntica Editora.

CELADA, M. T.; PAYER, M. (2016). O. Sobre sujeitos, língua(s), ensino. Notas para uma agenda. In: CELADA, M. T.; PAYER, M. O. (Org.). Subjetivação e processos de identificação. Sujeitos e línguas em práticas discursivas - inflexões no ensino. Campinas, SP: Pontes Editores.

CESARINO, L. (2018). On Digital Populism in Brazil. PoLAR: Political and Legal Antbropology Review. Disponível em: <https://polarjournal.org/2019/04/15/on-jair-bolsonarosdigital-populism/>

CESARINO, L. (2019). Entrevista à Revista Eletrônica de Jornalismo Científico. Disponível em: $<$ http://www.comciencia.br/leticia-cesarino-todo-populista-bem-sucedido-hojeprecisa-ser-tambem-um-bom-influenciador-digital/ $>$.

COLOMBO, L. A.; MARTELLI, C. G. G. (2015). O panelaço em perspectiva comparada: análise do fenômeno no Brasil e na Argentina. In: Anais do $39^{\circ}$ Encontro Anual da ANPOCS, Caxambu/MG.

COURTINE, J.-J. (2016). Definição de orientações teóricas e construção de procedimentos em Análise do Discurso. Policromias: Revista de Estudos do Discurso, Imagem e Som, Museu Nacional, UFRJ, n. 2, v. 1, p.14-35.

DELA-SILVA, S. (2012). Discurso, mídia e educação: da (não) obviedade de sentidos. In: MARIANI, B, MEDEIROS, V. (Org.). Discurso e...: ideologia, inconsciente, memória, desejo, movimentos sociais, cinismo, corpo, witz, rede eletrônica, língua materna, poesia, cultura, mídia, educação, tempo, (homo)sexualidade. Rio de Janeiro: 7Letras/ Faperj, p.179-198. 
DELA-SILVA, S.; SANTOS, R. G. (2018). A mídia e os dizeres sobre o professor: uma análise do discurso jornalístico. Cadernos de Letras da UFF, Niterói, v.57, p. 299-317.

FANJUL, A. P.; GONZÁLEZ, N. M. (Org.) (2014). Espanbol e português brasileiro: estudos comparados. $1^{\mathrm{a}}$ ed. São Paulo: Parábola Editorial.

FOUCAULT, M. (1969). A arqueologia do saber. $8^{\text {a }}$ ed., Rio de Janeiro: Forense Universitária, 2014.

GOHN, M.G. (2016). Manifestações de protesto nas ruas no Brasil a partir de Junho de 2013: novíssimos sujeitos em cena. Diálogo Educacional, PUCPR, Curitiba, v. 16, n.47, p. $125-146$.

GOLD, T. (2015). Cacerolazos y legitimidad política en la Argentina reciente. Del "13-S" al "8-A". In: ANNUNZIATA, R. (Org.). Pensar las elecciones: democracia, líderes y ciudadanos. Buenos Aires: Departamento de Publicaciones de la Facultad de Derecho y Ciencias Sociales de la Universidad de Buenos Aires.

LACLAU, E. (2005). A razão populista. São Paulo: Três Estrelas, 2013.

LAPOLLA CANTONI, S. (2016). Participação política não eleitoral na Argentina e no Brasil: (O que) mudou nas últimas décadas? Dissertação de mestrado. Faculdade de Filosofia, Letras e Ciências Humanas. Universidade de São Paulo.

MALY, I. (2018). Populism as a mediatized communicative relation: The birth of algorithmic populism. Tilburg Papers in Culture Studies, n² 213. Disponível em: <https:// www.researchgate.net/publication/328095323_Populism_as_a_mediatized_ communicative_relation_The_birth_of_algorithmic_populism $>$.

MALY, I. (2019). Algorithmic populism and algorithmic activism. Diggit Magazine. Disponível em: <https://www.diggitmagazine.com/articles/algorithmic-populism-activism>.

MARIANI, B. (1996). O comunismo imaginário: práticas discursivas da imprensa sobre o PCB (19221989). Tese de Doutorado. Pós-Graduação em Linguística. Instituto de Estudos da Linguagem, Universidade Estadual de Campinas (UNICAMP), São Paulo.

MARIANI, B. (1993). Os primórdios da imprensa no Brasil (Ou: de como o discurso jornalístico vai produzindo memória). In: ORLANDI, E. P. (Org.). Discurso fundador: a formação do país e a construção da identidade nacional. $2^{\text {a }}$ ed. Campinas: Pontes, 2001.

MARIANI, B. (2016). O político, o institucional e o pedagógico: quanto vale a língua que ensinamos? Matraga, n. 38, v. 23, Rio de Janeiro: jan/jun, p.43-63. 
NEGRI, A. (2014). Entrevista ao Caderno PoA. Disponível em: < http://zh.clicrbs.com.br/ rs/noticias/proa/noticia/2014/06/ antonio-negri-e-a-multidao-que-comanda-ahistoria-4520222.html >.

SERRANI, S. (2010). Discurso e cultura na aula de língua. Campinas: Pontes.

\section{FONTES JORNALÍSTICAS CONSULTADAS:}

"Seguridad, libertad y justicia", los principales reclamos de la gente (Clarín, 14/09/2012) $<$ https://drive.google.com/file/d/15iBEuDNJGuOCqjACLWhMkXD_fofPDyow/ view? $\mathrm{usp}=$ sharing $>$

Marchas, reclamos y acciones activan la participación social (Clarín, 02/06/2013) $<$ https://drive.google.com/file/d/1 igviQJ8AfRtDZ68sa3PyeDg22Wh50Drd/ view? $\mathrm{usp}=$ sharing $>$

Cacerolazo 18A: multitudinarias protestas contra el Gobierno en todo el país (La Nación, 18/04/2013) < https://drive.google.com/file/d/1kkBK8nmuNSobhQ27ZpDIfZTutlwE-bR/view $>$

Macri y el 18A: "Estoy del lado correcto" (La Nación, 19/04/2013) < https://drive.google. com/file/d/19LQjelCb8I2i7HJFMO_ZMMPb3aikeFcO/view? usp=sharing >

Para el kirchnerismo "hubo menos gente" (La Nación, 19/04/2013) < https://drive.google. com/file/d/12Ss3ficgxEI22S5Yuoalkk5bdGwF60ki/view? usp=sharing $>$

Cristina Kirchner criticó la protesta del 18A contra la reforma judicial (La Nación, 27/04/2013) $<$ https://drive.google.com/file/d/1JDjk2k_3tppdbPVQ9jaJQQHxC0-12mZI/ view? $\mathrm{usp}=$ sharing $>$

Indignação com a corrupção foi motivação para maioria nas ruas (Folba de S. Paulo, 15/03/2015) $<$ https://drive.google.com/file/d/1batimHofiXAsBnwwHABsTMzuK-48pjMe/ view? usp $=$ sharing $>$

Protestos de 15 de março (Folha de S. Paulo, 15/03/2015) < https://drive.google.com/file/ d/1yDEPZokU0IWUzKUwh3Q1VP-8borNB8Zz/view>

Adesão menor em protestos deixa Planalto aliviado (Folba de S. Paulo, 12/04/2015) < https:// drive.google.com/file/d/1mZK1 kukVD4vNNMyNSFxGCMTyxj5A-G2s/view> 
Eduardo e Jair Bolsonaro fazem "selfies" e distribuem abraços em SP (Folba de S. Paulo, 12/04/2015) < https://drive.google.com/file/d/1UYcjOlskEYgYaGx9dtXulhp6dmaCE $\mathrm{GlF} /$ view? $\mathrm{usp}=$ sharing $>$

Manifestantes também atacam a oposição em ato contra governo em SP (Folba de S. Paulo, 12/04/2015) < https://drive.google.com/file/d/15AVKv7fKUVgFGEcgD3ktK1 ca6IA_ yVG2/view? usp $=$ sharing $>$

Irritação com corrupção foi motivação para maioria (Folba de S. Paulo, 13/04/2015) $<$ https://drive.google.com/file/d/1sSB2hfrkmRpC84-Y2jO5g8KWgMe3wSKj/ view? $\mathrm{usp}=$ sharing $>$

Aécio diz que PT tenta 'tapar o sol com a peneira' ao acusar oposição de responsabilidades pelos protestos (O Globo, 09/03/2015) < https://drive.google.com/ file/d/1mEOOTEDvBuyLjOmibMPxU7RTxQG_XeOM/view? usp=sharing $>$

PT diz que panelaço fracassou e foi 'financiado' por partidos de oposição (O Globo, 09/03/2015) $<$ https://drive.google.com/file/d/1I9oGTqEX-SOEBGAaQDRBqviSodTf33I7/ view? $\mathrm{usp}=$ sharing $>$

Recebido: 29/3/2020

Aceito: 20/5/2020

Publicado: 26/6/2020 